\title{
Competing Role of Bioactive Constituents in Moringa oleifera Extract and Conventional Nutrition Feed on the Performance of Cobb 500 Broilers
}

\author{
Govindarajan Karthivashan, ${ }^{1}$ Palanisamy Arulselvan, ${ }^{1}$ Abd. Razak Alimon, ${ }^{2}$ \\ Intan Safinar Ismail, ${ }^{3}$ and Sharida Fakurazi ${ }^{1,4}$ \\ ${ }^{1}$ Laboratory of Vaccines and Immunotherapeutics, Institute of Bioscience, Universiti Putra Malaysia, \\ 43400 Serdang, Selangor, Malaysia \\ ${ }^{2}$ Department of Animal Science, Faculty of Agriculture, Universiti Putra Malaysia, 43400 Selangor, Malaysia \\ ${ }^{3}$ Laboratory of Natural Products, Institute of Bioscience (IBS), Universiti Putra Malaysia (UPM), 43400 Serdang, Selangor, Malaysia \\ ${ }^{4}$ Department of Human Anatomy, Faculty of Medicine and Health Sciences, Universiti Putra Malaysia, \\ 43400 Serdang, Selangor, Malaysia
}

Correspondence should be addressed to Sharida Fakurazi; sharida.fakurazi@gmail.com

Received 2 October 2014; Accepted 4 December 2014

Academic Editor: Hartmut Jaeschke

Copyright (C) 2015 Govindarajan Karthivashan et al. This is an open access article distributed under the Creative Commons Attribution License, which permits unrestricted use, distribution, and reproduction in any medium, provided the original work is properly cited.

\begin{abstract}
The influence of Moringa oleifera (MO) leaf extract as a dietary supplement on the growth performance and antioxidant parameters was evaluated on broiler meat and the compounds responsible for the corresponding antioxidant activity were identified. $0.5 \%, 1.0 \%$, and $1.5 \% \mathrm{w} / \mathrm{v}$ of MO leaf aqueous extracts (MOLE) were prepared, and nutritional feed supplemented with $0 \%, 0.5 \%, 1.0 \%$, and $1.5 \% \mathrm{w} / \mathrm{w}$ of MO leaf meal (MOLM) extracts were also prepared and analysed for their in vitro antioxidant potential. Furthermore, the treated broiler groups (control (T1) and treatment (T2, T3, and T4)) were evaluated for performance, meat quality, and antioxidant status. The results of this study revealed that, among the broilers fed MOLM, the broilers fed 0.5\% w/w MOLM (T2) exhibited enhanced meat quality and antioxidant status $(P<0.05)$. However, the antioxidant activity of the MOLE is greater than that of the MOLM. The LC-MS/MS analysis of MOLM showed high expression of isoflavones and fatty acids from soy and corn source, which antagonistically inhibit the expression of the flavonoids/phenols in the MO leaves thereby masking its antioxidant effects. Thus, altering the soy and corn gradients in conventional nutrition feed with $0.5 \% \mathrm{w} / \mathrm{w}$ MO leaves supplement would provide an efficient and cost-effective feed supplement.
\end{abstract}

\section{Introduction}

Poultry farming has grown since 2000, and the demand for broiler chicken meat has increased recently. From 2000 to 2010, both Africa and Asia have recorded increases of broiler meat production approximately 4.5 per cent a year, whereas growth in Europe has averaged 3.9 per cent, 3.7 per cent in Oceania and 3.5 per cent in the Americas [1]. For 2014, it is possible that the global indigenous chicken meat output will reach 95 million tons according to a forecast by the Food and Agriculture Organization (FAO). Chicken production also provides a base for the socioeconomic advancement in the majority of developing countries [2].
A primary reason for this increased demand for broiler meat is that consumers perceive that it as a healthy product that contains less fat, predominantly unsaturated fatty acids, and particularly polyunsaturated fatty acids, compared to beef or pork products [3].

The composition of the nutritional feed plays a major role in poultry meat production, which in general includes soy and corn as sources of energy and protein. In addition, the formulation of nutritional feed includes essential dietary supplements, which are important for improving the health and performance of the birds and also for enhancing the meat quality of human consumption [4]. In terms of meat quality, chicken muscle is enriched with polyunsaturated 
fatty acids, which is related to the increasing susceptibility of meat and meat products to fat oxidation with impaired organoleptic characteristics and decreased food shelf life [5]. Lipid peroxidation is the primary mechanism of meat decomposition and drives the necessity for antioxidant-enriched substances as an important constituent of feed supplements [6]. The advancement of poultry research has combined the knowledge of biochemical and physiological mechanisms to improve the efficiency of feed utilisation and increase desired attributes in response to changing dietary constituents [7]. Because of consumer preferences, despite the availability of synthetic antioxidants, food industries have focused on natural antioxidants as feed supplements since they are simple and cost-effective methods to achieve higher antioxidant stability, retain meat quality, and increase shelf life [8].

A major natural source of antioxidants is plants. The Miracle Tree or Moringa oleifera Lam. (MO) is postulated to have the highest antioxidant content in food and also has a remarkable range of medicinal uses and high nutritional value [9-14]. The leaves of this plant provide a rich source of carotenoids, vitamins, minerals, amino acids, alkaloids, and flavonoids and a rare combination of phenolic compounds, including zeatin, quercetin, kaempferol, apigenin, and many other phytoconstituents that offer essential and disease preventing nutrients to humans $[15,16]$. MO leaf meal has been recently evaluated for its effect on chicken meat growth and quality. MO leaves incorporated into maize meal poultry feed led to better growth performance of the chickens and a significant increase in the serum level of biochemical minerals compared to the maize meal feed alone [17]. Kakengi et al. [18] reported that MO leaf meal is a rich protein source that can be used as a substitute for sunflower seed meal at up to $20 \mathrm{mg} / \mathrm{kg}$ substitution without any detrimental effects in laying chickens. MO leaf meal has also been evaluated for the replacement of antibiotics in nutritional feed supplements and the results showed that MO leaf meal was a good replacement for oxytetracycline (antibiotic) in broilers [19]. Although several studies have reported the use of $\mathrm{MO}$ leaves as feed supplements in livestock [20-22], the optimal concentration of MO leaves as a nutritional supplement has not yet been determined, and there are only limited reports on the bioactive constituents of MO leaves and their impact on meat antioxidant status. The food industry, poultry farmers, and researchers must determine the best concentration of MO leaf supplement for broiler production with antioxidant-enriched meat. The objective of this study is to identify the optimal concentration of MO leaves as a nutritional supplement for broilers and also to identify and evaluate the bioactive constituents of both the MO leaves and conventional feed and their impact on broiler meat antioxidant status.

\section{Materials and Methods}

2.1. Leaves Extract Preparation and Feed Material Formulation. Fresh and mature leaves of $M$. oleifera were harvested locally from garden-2 of Universiti Putra Malaysia and were first air-dried for $12 \mathrm{~h}$ at room temperature $\left(24^{\circ} \mathrm{C}\right)$ and then oven-dried for two consecutive days, ground, and stored in air tight plastic bags until further processing. Initially, three various aqueous concentrations of MO leaf extracts (MOLE) were prepared ( $\mathrm{g}$ leaf powder: distilled water, $0.5 \mathrm{~g}: 1 \mathrm{~L}(0.5 \% \mathrm{w} / \mathrm{v}) ; 1 \mathrm{~g}: 1 \mathrm{~L}(1.0 \% \mathrm{w} / \mathrm{v})$; and $1.5 \% \mathrm{~g}: 1 \mathrm{~L}$ $(1.5 \mathrm{w} / \mathrm{v}))$ followed by maceration of the leaf powder in 3 different bottles for two days at room temperature. The corresponding residues were further condensed with a rotary evaporator at $40^{\circ} \mathrm{C}$, freeze-dried, and stored at $-80^{\circ} \mathrm{C}$ individually until further use. Subordinately, four concentrations of MO leaf meal (MOLM) extracts were prepared (g leaf powder: $g$ other feed constituents, $0 \mathrm{~g}: 100 \mathrm{~g}$ (0\% w/w); $0.5 \mathrm{~g}$ : $99.5 \mathrm{~g}(0.5 \% \mathrm{w} / \mathrm{w}) ; 1.0 \mathrm{~g}: 99 \mathrm{~g}(1.0 \% \mathrm{w} / \mathrm{w})$; and $1.5 \mathrm{~g}: 98.5 \mathrm{~g}(1.5 \% \mathrm{w} / \mathrm{w}))$. The MOLM feed formulations with concentrations are listed in Table 1.

2.2. Feeding Trial and Design. A feeding trial using Cobb 500 breed broiler chickens ( 23 weeks) was carried out on 160 birds retained in 6-tier battery cages ( $L: 0.5 \mathrm{~m}, W: 0.9 \mathrm{~m}$, and $H$ : $0.6 \mathrm{~m} /$ compartment) in a trial room with controlled climate and a light regimen of $16 \mathrm{~h}$ light: $8 \mathrm{~h}$ dark. The feed and water were provided ad libitum. The chickens were randomly divided into the following four groups: three treatment groups (T2 $(0.5 \% \mathrm{w} / \mathrm{w}), \mathrm{T} 3(1.0 \% \mathrm{w} / \mathrm{w})$, and T4 $(1.5 \% \mathrm{w} / \mathrm{w}))$ and one control group (T1 (only nutritional feed)). Each group had five replicates of 8 broilers per group. The trial lasted for 42 days, and, for the first 21 days, the birds were fed a commercial starter ration, followed by the experimental diet until day 42 . The experimental diet contains $20 \mathrm{mg}$ crude protein (CP) and $3050 \mathrm{kcal}$ metabolisable energy (ME)/kg supplemented with $0 \%, 0.5 \%, 1.0 \%$, and $1.5 \%$ MOLM, and the chickens were fed as shown in Table 1 . The chicks were inspected daily, and dead birds were removed after the mortality was recorded. The broiler chicks were weighed at the beginning of the experiment and then weekly. The feed allocation and total feed intake were also calculated weekly. The body weight (BW, g) was calculated as the final BW minus the initial BW, and the average weight gains (WG, g) were calculated accordingly. The feed intake (FI, g) was calculated as the feed allocated minus the feed refused, and the feed conversion ratio (FCR) was calculated as the FI (g) per BW $(\mathrm{g})$. The feeding trial was conducted in accordance with the guidelines of the Institutional Animal Care and Use Committee, Universiti Putra Malaysia, which regulate and monitor the use and welfare of animals in experiments.

2.3. Sample Preparation and Analysis. On the $42 \mathrm{nd}$ day, the experimental birds were weighed and sacrificed using the halal procedure by severing the jugular veins. The liver, kidney, breast, and thigh muscles were carefully excised, packed in polyethylene bags, flash-frozen in liquid nitrogen, and stored at $-80^{\circ} \mathrm{C}$ until use. The carcasses were dressed by removing the head, feet, skin, and viscera, and the dressing percentage was calculated using the formula (= carcass weight $(\mathrm{CW}) /$ live weight $(\mathrm{LW}) * 100)$. The bones, muscles (meat), and fat were carefully trimmed from the carcass and weighed accordingly to calculate the meat : bone : fat ratio for each dietary treatment. Two samples from each replicate of the meat samples stored at $-80^{\circ} \mathrm{C}$ were removed and weighed immediately $\left(W_{1}\right)$. The samples were then dried 
TABLE 1: Composition of experimental diet.

\begin{tabular}{|c|c|c|c|c|}
\hline Feed stuff ingredients (\%) & $\begin{array}{c}\text { Control } \\
\mathrm{T} 1\end{array}$ & $\begin{array}{c}0.5 \% \text { MOLM } \\
\text { T2 }\end{array}$ & $\begin{array}{c}1.0 \% \text { MOLM } \\
\text { T3 }\end{array}$ & $\begin{array}{c}1.5 \% \text { MOLM } \\
\text { T4 }\end{array}$ \\
\hline Moringa oleifera leaves meal & 0 & 0.5 & 1.0 & 1.5 \\
\hline Corn & 61 & 60.5 & 60.5 & 60.5 \\
\hline Soybean meal & 27 & 27 & 26.5 & 26 \\
\hline Fish meal & 5 & 5 & 5 & 5 \\
\hline Palm oil & 4 & 4 & 4 & 4 \\
\hline Salt & 0.25 & 0.25 & 0.25 & 0.25 \\
\hline Limestone & 1 & 1.0 & 1.0 & 1.0 \\
\hline Dicalcium phosphate & 0.5 & 0.5 & 0.5 & 0.5 \\
\hline Minerals & 0.25 & 0.25 & 0.25 & 0.25 \\
\hline Vitamins & 0.25 & 0.25 & 0.25 & 0.25 \\
\hline DL-Methionine & 0.15 & 0.15 & 0.15 & 0.15 \\
\hline Lysine & 0.5 & 0.5 & 0.5 & 0.5 \\
\hline Choline chloride & 0.1 & 0.1 & 0.1 & 0.1 \\
\hline Total & 100 & 100 & 100 & 100 \\
\hline
\end{tabular}

carefully with absorbent paper and weighed again $\left(W_{2}\right)$ to calculate the drip loss using the formula $\left(=W_{1}-W_{2} / W_{1} *\right.$ 100). Two samples from each replicate of the meat samples were preweighed $\left(w_{1}\right)$ and then cooked in a water bath at $80^{\circ} \mathrm{C}$ for $20 \mathrm{~min}$ and cooled for $30 \mathrm{~min}$ to obtain the weight of the cooked sample $\left(w_{2}\right)$. The cooking loss was calculated with the formula $\left(=w_{1}-w_{2} / w_{1} * 100\right)$. The meat color and tenderness were measured on three samples from each replicate based on the L (lightness), a (redness), and $\mathrm{b}$ (yellowness) using the HunterLab system (Colour Flex, USA). For the measurement of meat tenderness, three cores were obtained from each sample and sheared at two locations using a texture analyser (Stable Micro Systems, UK) with a Warner-Bratzler blade. The shear force values were then reported.

2.4. Antioxidant Activity. A comparative analysis was performed for the in vitro antioxidant activities of the MOLE $(0.5 \% \mathrm{w} / \mathrm{v}, 1.0 \% \mathrm{w} / \mathrm{v}$, and $1.5 \% \mathrm{w} / \mathrm{v})$ and MOLM $(0 \% \mathrm{w} / \mathrm{w}$, $0.5 \% \mathrm{w} / \mathrm{w}, 1.0 \% \mathrm{w} / \mathrm{w}$, and $1.5 \% \mathrm{w} / \mathrm{w})$ using DPPH radical scavenging and phosphomolybdenum total antioxidant capacity assays as described by Karthivashan et al. [9]. The liver, kidney, breast, and thigh muscles from the treated broiler chicks that were stored at $-80^{\circ} \mathrm{C}$ were thawed, homogenized, and centrifuged, and the supernatants were assayed according to the kit instructions from the Cayman Chemical Company (Ann Arbor, U.S.A.) to determine the LPO according to standard procedures using LPO (Item number 705002) and the activity of the antioxidant enzymes SOD (Item number 706002), CAT (Item number 707002), and GPx (Item number 703102).

2.5. Chromatography Instrumentation and Conditions. Chromatographic separation of the compounds in the $0.5 \% \mathrm{w} / \mathrm{v}$, $1.0 \% \mathrm{w} / \mathrm{v}$, and $1.5 \% \mathrm{w} / \mathrm{v}$ aqueous $\mathrm{MO}$ leaf extracts (MOLE) was performed with a LUNA C18 $(4 \times 250 \mathrm{~mm}, 5 \mu \mathrm{m})$ Phenomenex column (Torrance, California, U.S.A.) on an Agilent 1100 series HPLC system (Santa Clara, California,
U.S.A.) equipped with a binary pump, diode array detector (DAD) (200 to $600 \mathrm{~nm}$ ), and autosampler. The sample injection volume was $20 \mu \mathrm{L}$ with a mobile phase flow rate of $1.0 \mathrm{~mL} / \mathrm{min}$ monitored at a wavelength of $254 \mathrm{~nm}$. The mobile phase consisted of solvent $A$, distilled water, and solvent $B$, methanol: distilled water $70: 30(\mathrm{v} / \mathrm{v})$. The gradient program profile was a combination of solvents $\mathrm{A}$ and $\mathrm{B}$ as follows: 0 to $10 \mathrm{~min}, 30 \%$ solvent $\mathrm{B}$; 10 to $20 \mathrm{~min}, 40 \%$ solvent $\mathrm{B} ; 20$ to $35 \mathrm{~min}, 50 \%$ solvent $\mathrm{B}$; 35 to $40 \mathrm{~min}, 60 \%$ solvent $\mathrm{B}$; 40 to $45 \mathrm{~min}, 70 \%$ solvent B; and 45 to $50 \mathrm{~min}, 0 \%$ solvent B.

The compounds in the $0.5 \mathrm{w} / \mathrm{v}$ aqueous $\mathrm{MO}$ leaf extracts (MOLE) and $0.5 \mathrm{w} / \mathrm{w}$ MO leaf meal (MOLM) extracts were identified with accurate mass detection using an AB Sciex 3200 QTrap LCMS/MS with a Perkin Elmer FX 15 UHPLC system (MA, USA). The negative ion mass spectra were obtained with a LC QTrap MS/MS detector in full ion scan mode (100 to $1200 \mathrm{~m} / z$ for full scan and $50-1200 \mathrm{~m} / z$ for MS/MS scan) at a scan rate of $0.5 \mathrm{~Hz}$. The system was supported with mass spectrometry software and a spectral library provided by ACD labs (Toronto, ON, Canada). Analyte separation was performed on a C18 column $(4 \times 250 \mathrm{~mm}$, $5 \mu \mathrm{m}$, Phenomenex) with a gradient mobile phase consisting of water (solvent A) and methanol with $1 \%$ acetonitrile (solvent B), each containing $0.1 \%$ formic acid and $5 \mathrm{mM}$ ammonium format. The gradient program was $40 \%$ solvent B to $50 \%$ solvent $B$ over $11.00 \mathrm{~min}$ at a flow rate of $1.0 \mathrm{~mL} / \mathrm{min}$. The sample injection volume was $20 \mu \mathrm{L}$. All chromatographic procedures were performed at ambient temperature, and the corresponding peaks from the QTrap LCMS/MS analysis of both the $0.5 \mathrm{w} / \mathrm{v}$ MOLE and $0.5 \mathrm{w} / \mathrm{w}$ MOLM were identified by comparison with the literature/ACD labs mass spectral library.

2.6. Statistical Analysis. All data from the in vitro and in vivo experiments were obtained from triplicate experiments and were expressed as the mean \pm S.E.M. The statistical analysis was carried out by analysis of variance (ANOVA) followed by 
Tukey's test using the IBM-SPSS Statistics software, version 20 (Armonk, NY, U.S.A.). The significance level was set at $P<0.05$.

\section{Results}

3.1. In Vitro Antioxidant Activity. The in vitro antioxidant activity of the MO leaf extracts (MOLE) and MO leaf meal (MOLM) extracts were comparatively evaluated with DPPH, nitric oxide (NO) radical scavenging assay, and phosphomolybdenum (PMO) total antioxidant capacity assays. For the DPPH and NO assays, the changes in the ability of the MO leaf extracts (MOLE) and MO leaf meal (MOLM) extracts to scavenge free DPPH and NO radicals were calculated as the percentage inhibition and are shown in Figures 1(a) and $1(b)$, respectively. The results indicate that $0.5 \mathrm{w} / \mathrm{v}$ MOLE has significant $(P<0.05)$ free radical scavenging activity, with the lowest $\mathrm{IC}_{50}$ values of 154.5 and 56.4 for DPPH and NO, respectively, compared to the other extracts. For the MOLM extracts, $0.5 \% \mathrm{w} / \mathrm{w}$ MOLM has the highest scavenging activity with $\mathrm{IC}_{50}$ values of 229.4 and 134.5 for $\mathrm{DPPH}$ and $\mathrm{NO}$, respectively, but these values are not as low as the $0.5 \% \mathrm{w} / \mathrm{V}$ MOLE. The nutritional feed alone ( $0 \% \mathrm{w} / \mathrm{w}$ MOLM) shows the least scavenging activity with $\mathrm{IC}_{50}$ values of 378 and 298 for $\mathrm{DPPH}$ and $\mathrm{NO}$, respectively, although the $\mathrm{IC}_{50}$ values for $1.5 \% \mathrm{w} / \mathrm{w}$ MOLM are higher than $0 \mathrm{w} / \mathrm{w}$ MOLM (control) for NO radical scavenging activity. For the PMO total antioxidant capacity assay, we determined whether the MO leaf extract (MOLE) and MO leaf meal (MOLM) extracts reduce phosphomolybdic acid to phosphomolybdic blue $\left(\mathrm{Mo}_{+6} \rightarrow\right.$ $\left.\mathrm{Mo}_{+5}\right)$, and this was expressed quantitatively in terms of ascorbic acid equivalent $\mu \mathrm{g} / \mathrm{g}$ of extract in Figure 1(c). The results were consistent with the DPPH and NO assay results. The $0.5 \% \mathrm{w} / \mathrm{v}$ MOLE had the highest antioxidant capacity $(P<0.05)$ of all concentrations, with 36.26 ascorbic acid equivalent $\mu \mathrm{g} / \mathrm{g}$ of extract. However, for the other MOLM concentration, $0.5 \% \mathrm{w} / \mathrm{w}$ MOLM has the highest antioxidant capacity $(P<0.05)$, with 34.66 ascorbic acid equivalent $\mu \mathrm{g} / \mathrm{g}$ of extract, and the control ( $0 \% \mathrm{w} / \mathrm{w}$ MOLM) has the lowest activity, with 22.63 ascorbic acid equivalent $\mu \mathrm{g} / \mathrm{g}$ of extract.

\subsection{Broiler Growth Performance, Carcass, and Meat Quality}

3.2.1. Growth Performance. The average weight gain, feed intake (FI), feed conversion ratio (FCR), and mortality for the treatment period of 22-42 days are reported in Table 2(a). Broilers fed MOLM (T2, T3, and T4) show significant $(P<$ 0.05 ) weight gain compared to broilers fed nutritional feed only (T1), although there were no significant differences in weight gain for the dietary treatments.

3.2.2. Feed Conversion Ratio. The feed conversion ratio (FCR) data from Table 2(a) indicates that the broilers fed nutritional feed alone (T1: control group) show significantly $(P<0.05)$ highest FCR value of $2.67 \pm 0.052$ compared to all the dietary treatment groups (T2, T3, and T4). Throughout the experimental period, approximately $2 \%$ mortality was observed for all groups, and there were no significant differences, except for group T2 with $8 \%$ mortality, which caused the anomaly.

3.2.3. Carcass Characteristics. Table 2(b) shows the average dressing percentage, meat:bone, meat: fat, and bone:fat ratio of the MOLM fed broilers. The result indicates that the broilers fed MOLM (T2, T3, and T4) have significantly $(P<0.05)$ higher dressing percentages than the broilers fed nutritional feed alone (T1: control). Of the MOLM concentrations (T2, T3, and T4), the dressing percentages were significantly $(P<0.05)$ different, ranging from 67 to $70 \%$, and T3 (1.0\% w/w MOLM) showed the highest dressing percentage of $70 \%$. The meat : bone and meat : fat ratios were significantly $(P<0.05)$ different among the treated birds, with values ranging 3.459-3.814 and 6.31-8.43, respectively.

3.2.4. Meat Quality. Table 2(c) shows the average cooking loss, drip loss, color, and tenderness of the MOLM fed broiler meat. The data in Table 2(c) indicate significant differences among all treatment groups $(P<0.05)$ for cooking loss and drip loss. The treatment groups (T2, T3, and T4) exhibited significantly higher drip loss values compared to the control group (T1), which had the lowest drip loss value. By contrast, the control group (T1), T3, and T4 exhibited the highest cooking loss without any significant difference among the groups, compared to T2 with the lowest cooking loss value of $16.62 \%$. The percentage of cooking loss ranged from 16.62 to $21.99 \%$. Table 2 (c) shows the average color of the meat determined by the lightness $\left(\mathrm{L}^{*}\right)$, redness $\left(\mathrm{a}^{*}\right)$, and yellowness $\left(b^{*}\right)$ of broiler chickens fed MOLM supplements. As expected, the broiler chicken breast meat exhibited greater yellowness $\left(b^{*}\right)$ than redness $\left(a^{*}\right)$. For lightness, there was no significant difference between T2 and T4. However, T3 showed a significantly $(P<0.05)$ higher lightness value of 51.70. For redness, there was no significant difference between $\mathrm{T} 1$ and $\mathrm{T} 4$; however, $\mathrm{T} 2$ is significantly different $(P<0.05)$ from T3 and possesses the highest value of 7.93. Although there are slight differences among all the treatments, T4 exhibited the highest yellowness value of 14.24. Table 2(c) shows the average tenderness of broiler chicken meat fed with varying concentrations of MOLM supplement. The shear value indicates the degree of tenderness. There was no significant difference among the treatment groups; however, the T2 group showed a significantly higher value meat tenderness of 1.23 compared to T1, T3, and T4.

3.3. Lipid Peroxidation (MDA) Levels and Antioxidant Enzymes Activities in Chicken Muscles and Organs. The impact of MOLM feed supplements on the lipid peroxidation (MDA) levels in the liver, kidney, breast, and thigh muscles of treated broilers is shown in Figure 2(a). The extent of lipid peroxidation in the muscle and organ samples was measured by MDA formation. Figures 2(a)(a1) and 2(a)(a2) clearly show that the MDA formation in the breast, thigh, liver, and kidney of broilers treated with MOLM (T2, T3, and T4) were significantly $(P<0.05)$ lower than the control group (T1). The results were also significantly different among all the treatment groups $(P<0.05)$ except for kidney. Group T3 was not significantly different from the 


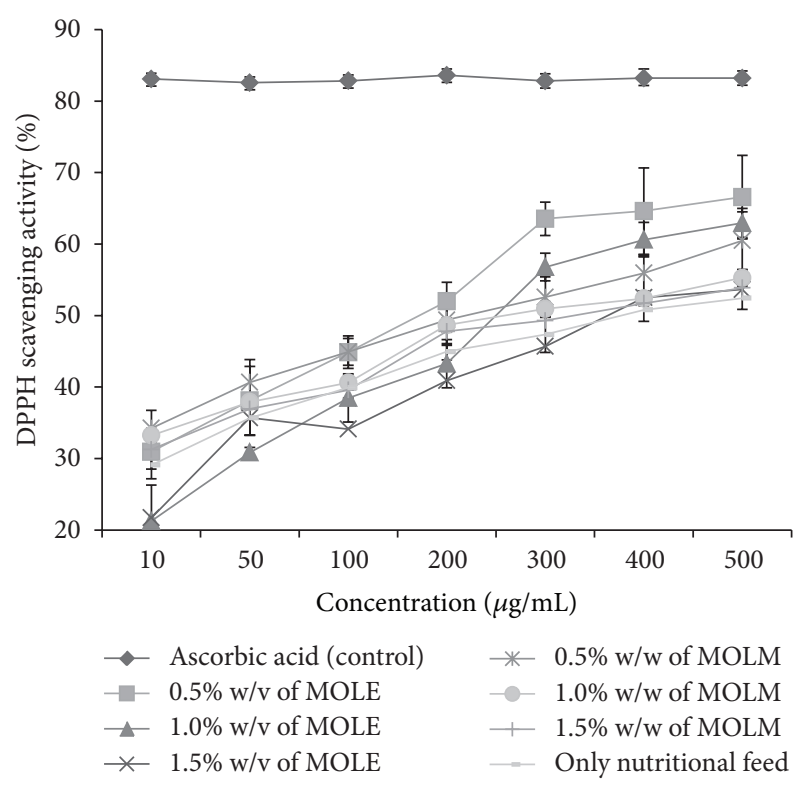

(a)

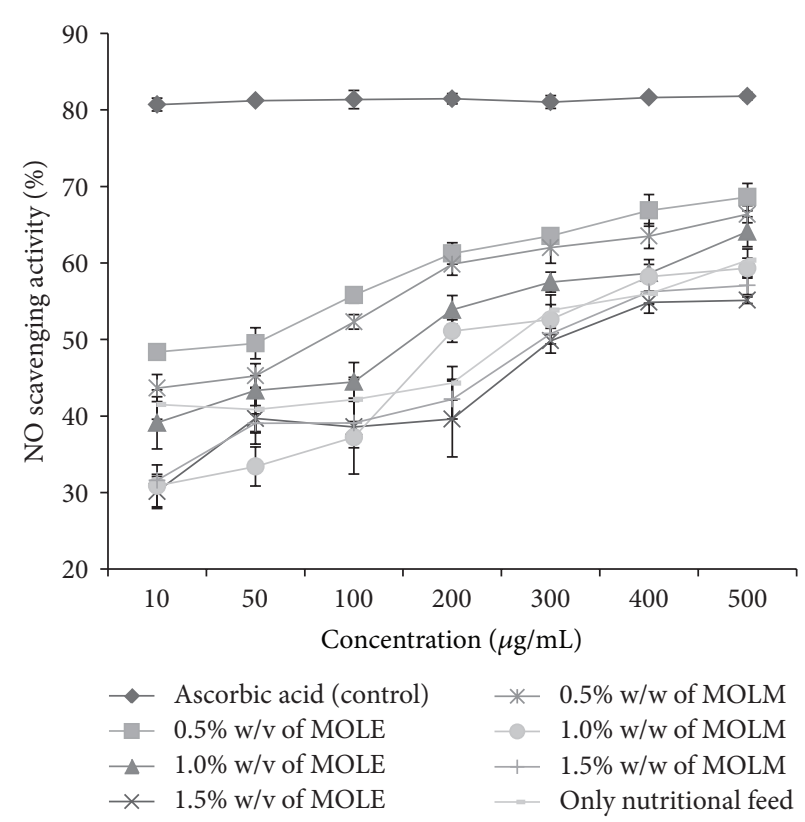

(b)

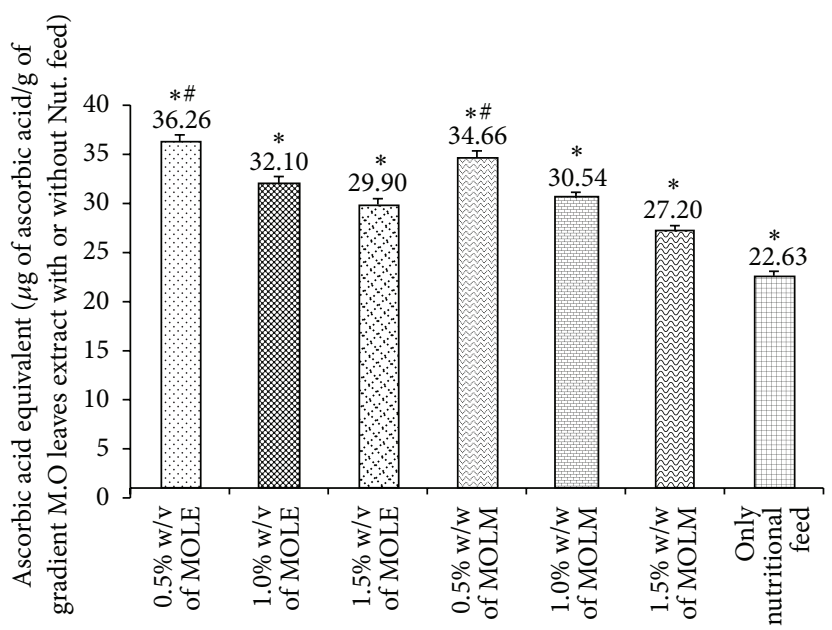

(c)

FIGURE 1: In vitro antioxidant activity of MOLE and MOLM extracts. (a) DPPH radical scavenging activity; (b) NO scavenging activity; and (c) total antioxidant capacity of varying gradient Moringa oleifera leaves extracts (MOLE) $(0.5 \%, 1.0 \%$, and $1.5 \%$ w/v) and Moringa oleifera leaves meal (MOLM) extracts $(0 \%, 0.5 \%, 1.0 \%$, and $1.5 \% \mathrm{w} / \mathrm{w})$ with/without nutritional feed at different concentrations $(10-500 \mu \mathrm{g} / \mathrm{mL}) \mathrm{were}$ determined spectrophotometrically at $540 \mathrm{~nm}, 540 \mathrm{~nm}$, and $630 \mathrm{~nm}$ respectively. Results are means \pm SD of three duplicate measurements. (DPPH: 1,1-diphenyl-2-picryl-hydrazyl free radical; NO: Nitric oxide free radical). In (a) and (b), the control compared to gradient extract with or without nutritional feed is statistically significant $(P<0.05)$. In $(\mathrm{c}),{ }^{*} P<0.05$ compared to only nutritional feed and ${ }^{\#} P<0.05$ compared to other gradient extracts.

control group. However, T2 (0.5\% w/w MOLM) showed the lowest MDA formation in both the muscles and organs, indicating suppressed lipid peroxidation activity. Changes in the activities of the antioxidant enzymes SOD, CAT, and GPx in the muscles (breast and thigh) and organs (liver and kidney) of broilers fed MOLM feed supplement are shown in Figure 2. Figure 2(b)(b1) shows no significant difference in SOD levels of the broiler tissues for the MOLM treated groups and control groups. However, T2 (0.5\% w/w MOLM) had the highest SOD level in both the breast and thigh muscles compared to the other treatment groups. The SOD levels in the thigh are greater than the breast tissue, particularly for T2. By contrast, Figure 2(b)(b2) shows significant differences in the SOD levels of the liver and kidney for the MOLM treated groups (T2, T3, and T4) and control group (T1). However, the SOD level in the kidney of group T3 showed was not significantly different from the control group. Group T2 (0.5\% w/w MOLM) had a significantly high level of SOD in both the muscles and organs compared to the control group (T1). Figures 2(c)(c1) and 2(c)(c2) also show a similar 
TABLE 2: Growth performance, carcass characteristics, and meat quality (mean \pm SE).

(a) Growth performance

\begin{tabular}{lcccc}
\hline & & \multicolumn{2}{c}{ Treatment groups } \\
Parameters & $\begin{array}{c}\text { Nutritional feed only } \\
\text { (T1) }\end{array}$ & $\begin{array}{c}0.5 \% \text { w/w of MOLM } \\
\text { (T2) }\end{array}$ & $\begin{array}{c}1.0 \% \text { w/w of MOLM } \\
\text { (T3) }\end{array}$ & $\begin{array}{c}1.5 \% \text { w/w of MOLM } \\
(\mathrm{T} 4)\end{array}$ \\
\hline Final body weight (g) 42 d & $2091 \pm 45.9^{\mathrm{b}}$ & $2222 \pm 25.3^{\mathrm{a}}$ & $2263 \pm 30.2^{\mathrm{a}}$ & $2218 \pm 47.6^{\mathrm{a}}$ \\
Initial body weight (g) 42 d & $707 \pm 4.38^{\mathrm{a}}$ & $705 \pm 6.09^{\mathrm{a}}$ & $702 \pm 4.68^{\mathrm{a}}$ & $701 \pm 5.81^{\mathrm{a}}$ \\
Weight gain (g/day) 22-42 d & $66 \pm 1.986^{\mathrm{b}}$ & $72 \pm 1.285^{\mathrm{a}}$ & $75 \pm 1.439^{\mathrm{a}}$ & $72 \pm 2.409^{\mathrm{a}}$ \\
Feed intake (g/day) 22-42 d & $175 \pm 2.05^{\mathrm{a}}$ & $178 \pm 0.85^{\mathrm{a}}$ & $174 \pm 1.4^{\mathrm{a}}$ & $165 \pm 1.16^{\mathrm{b}}$ \\
FCR 22-42 d & $2.67 \pm 0.052^{\mathrm{a}}$ & $2.47 \pm 0.037^{\mathrm{b}}$ & $2.32 \pm 0.027^{\mathrm{bc}}$ & $2.30 \pm 0.065^{\mathrm{c}}$ \\
Mortality (\%) 22-42 d & $3 \pm 2.5$ & $8 \pm 5.0$ & $2 \pm 2.5$ & $3 \pm 2.5$ \\
\hline
\end{tabular}

(b) Carcass characteristics

\begin{tabular}{lcccc}
\hline Parameters & \multicolumn{3}{c}{ Treatment groups } \\
& $\begin{array}{c}\text { Nutritional feed only } \\
(\mathrm{T} 1)\end{array}$ & $\begin{array}{c}0.5 \% \mathrm{w} / \mathrm{w} \text { of MOLM } \\
(\mathrm{T} 2)\end{array}$ & $\begin{array}{c}1.0 \% \text { w/w of MOLM } \\
(\mathrm{T} 3)\end{array}$ & $\begin{array}{c}1.5 \% \text { w/w of MOLM } \\
(\mathrm{T} 4)\end{array}$ \\
\hline Dressing percentage & $65.97 \pm 0.074^{\mathrm{d}}$ & $67.07 \pm 0.042^{\mathrm{c}}$ & $70.15 \pm 0.219^{\mathrm{a}}$ & $68.56 \pm 0.114^{\mathrm{b}}$ \\
Meat bone & $3.459 \pm 0.016^{\mathrm{b}}$ & $3.412 \pm 0.024^{\mathrm{b}}$ & $3.814 \pm 0.027^{\mathrm{a}}$ & $3.712 \pm 0.050^{\mathrm{a}}$ \\
Meat : fat & $6.31 \pm 0.016^{\mathrm{d}}$ & $7.89 \pm 0.030^{\mathrm{b}}$ & $8.43 \pm 0.045^{\mathrm{b}}$ & $6.83 \pm 0.040^{\mathrm{c}}$ \\
Bone $:$ fat & $3.91 \pm 1.13^{\mathrm{b}}$ & $3.65 \pm 1.16^{\mathrm{a}}$ & $3.54 \pm 0.51^{\mathrm{a}}$ & $3.79 \pm 0.46^{\mathrm{a}}$ \\
\hline
\end{tabular}

(c) Meat quality

\begin{tabular}{|c|c|c|c|c|}
\hline \multirow[b]{2}{*}{ Parameters } & \multicolumn{4}{|c|}{ Treatment groups } \\
\hline & $\begin{array}{l}\text { Nutritional feed only } \\
\text { (T1) }\end{array}$ & $\begin{array}{l}0.5 \% \text { w/w of MOLM } \\
\text { (T2) }\end{array}$ & $\begin{array}{c}1.0 \% \text { w/w of MOLM } \\
\text { (T3) }\end{array}$ & $\begin{array}{c}1.5 \% \mathrm{w} / \mathrm{w} \text { of MOLM } \\
(\mathrm{T} 4)\end{array}$ \\
\hline Cooking loss (\%) & $21.99 \pm 0.464^{\mathrm{a}}$ & $16.62 \pm 0.619^{b}$ & $21.66 \pm 1.441^{\mathrm{a}}$ & $20.34 \pm 1.141^{\mathrm{a}}$ \\
\hline Drip loss (\%) & $5.72 \pm 0.027^{\mathrm{d}}$ & $5.94 \pm 0.028^{\mathrm{c}}$ & $8.01 \pm 0.034^{\mathrm{a}}$ & $7.74 \pm 0.065^{\mathrm{b}}$ \\
\hline Lightness & $46.70 \pm 1.193^{b}$ & $46.24 \pm 0.373^{\mathrm{b}}$ & $51.70 \pm 0.827^{\mathrm{a}}$ & $47.25 \pm 0.513^{\mathrm{b}}$ \\
\hline Redness & $6.15 \pm 0.583^{\mathrm{ab}}$ & $7.93 \pm 0.793^{\mathrm{a}}$ & $5.45 \pm 0.450^{\mathrm{b}}$ & $6.64 \pm 0.497^{\mathrm{ab}}$ \\
\hline Yellowness & $12.08 \pm 0.604^{\mathrm{b}}$ & $13.52 \pm 0.384^{\mathrm{ab}}$ & $13.15 \pm 0.537^{\mathrm{ab}}$ & $14.24 \pm 0.584^{\mathrm{a}}$ \\
\hline Tenderness & $1.07 \pm 0.1^{\mathrm{a}}$ & $1.23 \pm 0.19^{\mathrm{a}}$ & $0.94 \pm 0.07^{\mathrm{a}}$ & $0.89 \pm 0.007^{\mathrm{a}}$ \\
\hline
\end{tabular}

Table 2(a) (growth performance): the final body weight, weight gain, feed intake, feed conversion ratio, and mortality $\left({ }^{*}\right.$ a, b values for final body weight, weight gain, and feed intake showing different superscripts within rows are significantly different $(P<0.05)$ and the ${ }^{*} \mathrm{a}$, b, bc, and $\mathrm{c}$ within rows of the FCR are significantly different $(P<0.05)$ ). Table $2(\mathrm{~b})$ (carcass characteristics): the dressing percentage and meat: bone: fat ratio $\left({ }^{*} \mathrm{a}, \mathrm{b}, \mathrm{c}\right.$, and $\mathrm{d}$ values for dressing percentage and meat : bone : fat ratio within rows are significantly different $(P<0.05)$ ). Table $2(\mathrm{c})$ (meat quality): the cooking loss, drip loss, color, and tenderness $\left({ }^{*} \mathrm{a}, \mathrm{b}, \mathrm{c}, \mathrm{d}\right.$ values with different superscripts on the same row are significantly different $\left.(P<0.05)\right)$, of broiler chicken fed with various gradients of Moringa oleifera leaves meal $(0.5 \%, 1.0 \%$, and $1.5 \%$ w/w) MOLM with/without nutritional feed.

trend because the catalase enzyme levels for T2 $(0.5 \% \mathrm{w} / \mathrm{w}$ MOLM) in the breast, thigh, and liver were significantly higher compared to the other treatment and control groups, except for the kidney, in which T3 showed high catalase level, with a small difference for the T2 group. Although the thigh and kidney showed significant differences for all the treatment groups $(P<0.05)$ and control, no significant differences were observed in the breast and liver. Overall, T2 (0.5\% w/w MOLM) showed significantly high levels of catalase in both the muscles and organs compared to the control group (T1), except the kidney of T3, possibly because of an anomaly. Figure $2(\mathrm{~d})(\mathrm{d} 1)$ shows a significant difference in the GPx activity levels of broilers tissues for the MOLM treated groups and control group, in which T2 $(0.5 \% \mathrm{w} / \mathrm{w}$ MOLM) showed the highest GPx level in both the breast and thigh muscles compared to the other treatment groups. The thigh muscle of the T3 group (1.0\% w/w MOLM) showed an unexpected drop in the GPx level, with no significant difference with the control group (T1). Figure $2(\mathrm{~d})(\mathrm{d} 2)$ shows a significant $(P<0.05)$ increase in the level of GPx activity in both the kidney and the liver of T2 $(0.5 \% \mathrm{w} / \mathrm{w}$ MOLM) and T3 (1.0\% MOLM) and a nonsignificant decrease in the GPx level in T4 (1.5\% w/w MOLM) compared to the control group (T1). However, T2 $(0.5 \% \mathrm{w} / \mathrm{w}$ MOLM) showed the highest GPx levels in both the muscles and the organs compared to the control.

3.4. Bioactive Constituents and Their Role in MOLE and MOLM. The HPLC fingerprints of $0.5 \% \mathrm{w} / \mathrm{v}, 1.0 \% \mathrm{w} / \mathrm{v}$, and $1.5 \% \mathrm{w} / \mathrm{v}$ MOLE showed the same profile of peaks (Figures 3(a), 3(b), and 3(c)). A few peaks were uniquely expressed during 10-30 min retention time of the $0.5 \% \mathrm{w} / \mathrm{V}$ MOLE (Figure 3(a)), which may be responsible for its high antioxidant activity. Furthermore, LC-MS/MS analysis of 


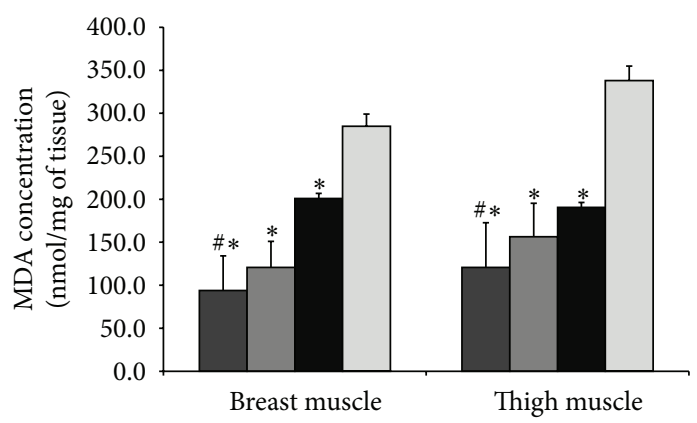

(a1)

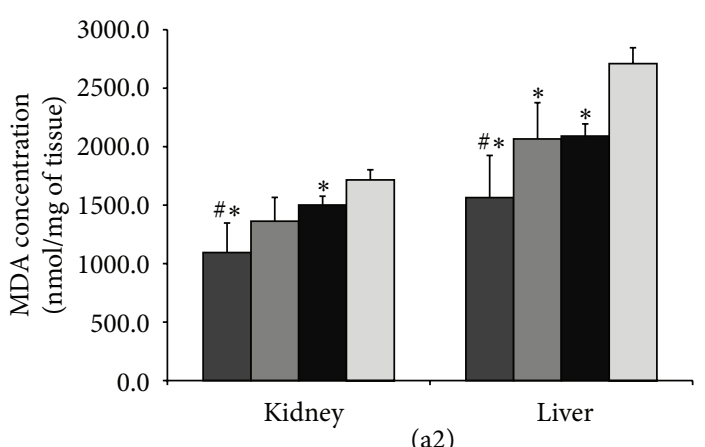

(a)

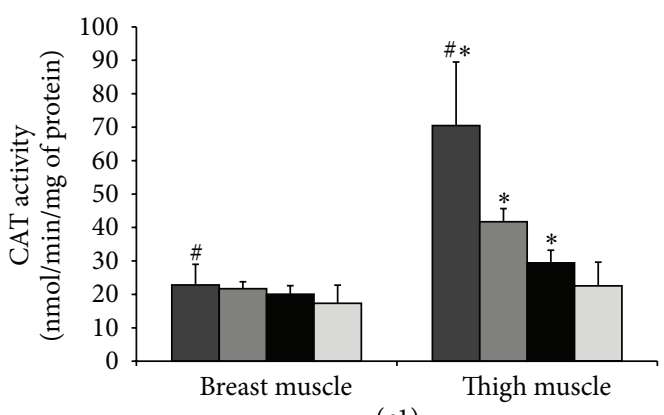

(c1)

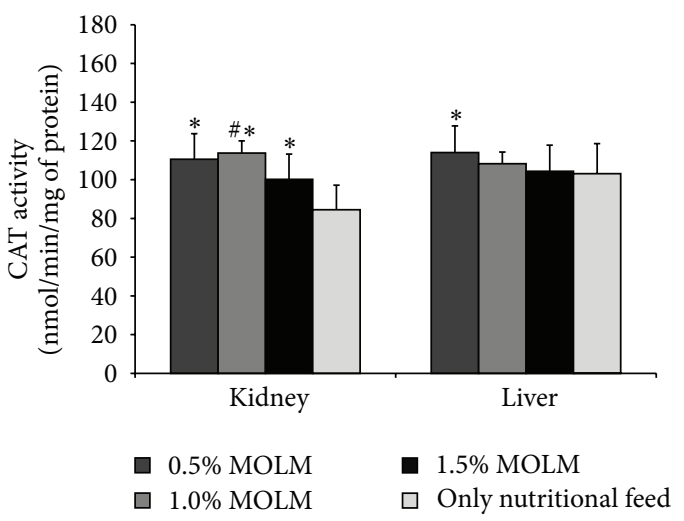

(c2)

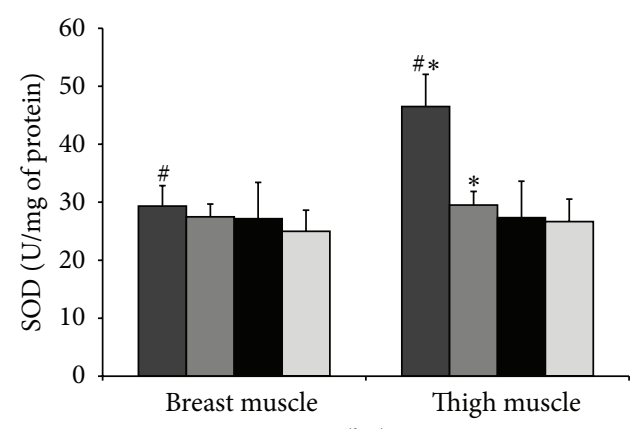

(b1)

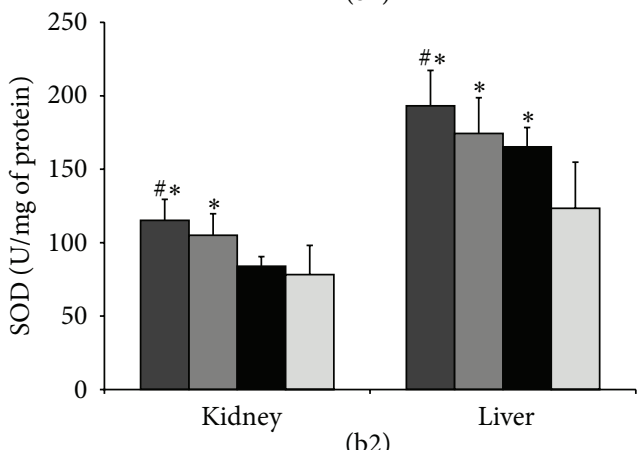

(b)

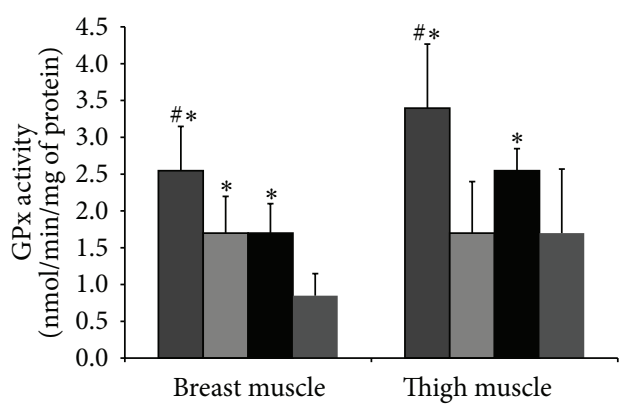

(d1)

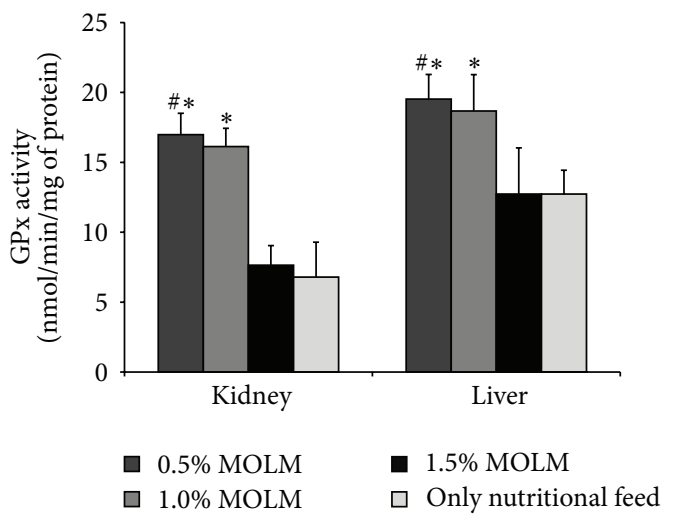

(d2)

(c)

(d)

Figure 2: Antioxidant enzymes (MDA, SOD, CAT, and GPx) level in chicken muscles and organs. (a) Total malonaldehyde (MDA); (b) SOD activity; (c) catalase activity; and (d) glutathione peroxidase (GPx) activity of different muscles (breast and thigh) and organs (liver and kidney) of chicken fed with various gradient Moringa oleifera leaves extracts $(0.5 \%, 1.0 \%$, and $1.5 \% \mathrm{w} / \mathrm{w})$ with nutritional feed/nutritional feed alone were determined. Results are means \pm SD of three duplicate measurements. ${ }^{*} P<0.05$ compared to only nutritional feed and ${ }^{\#} P<0.05$ compared to other gradient extracts. 


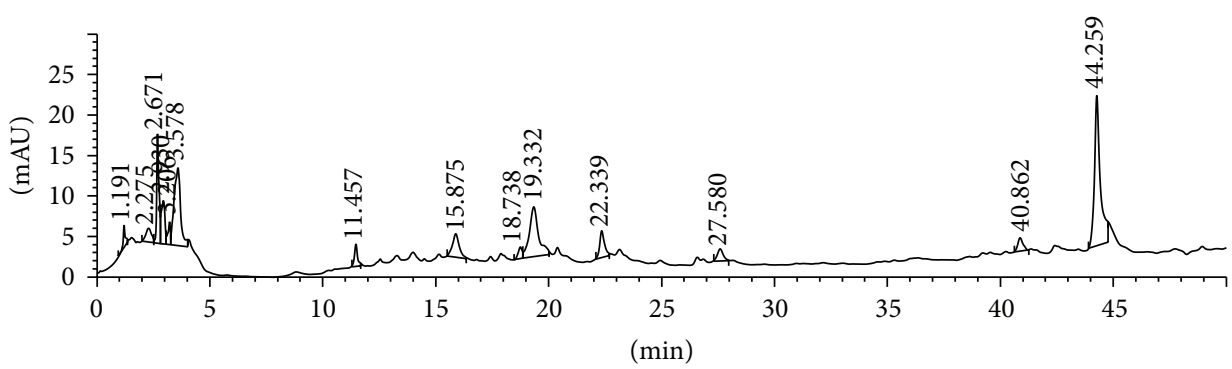

(a)

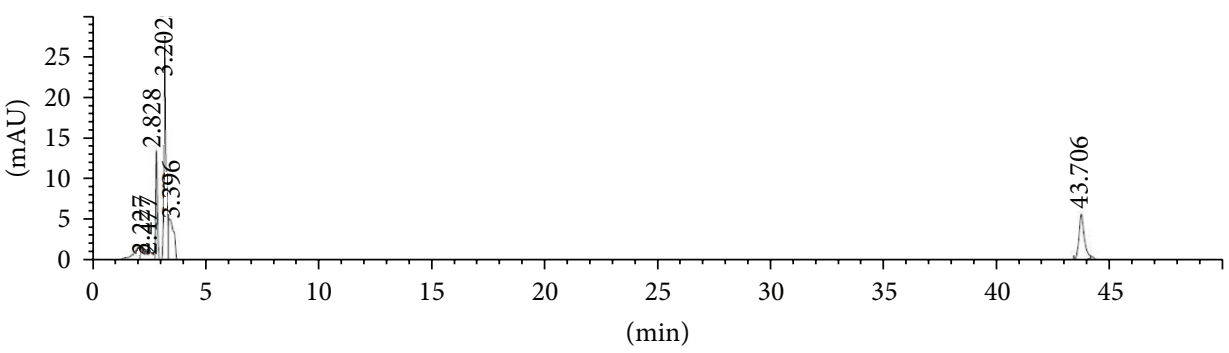

(b)

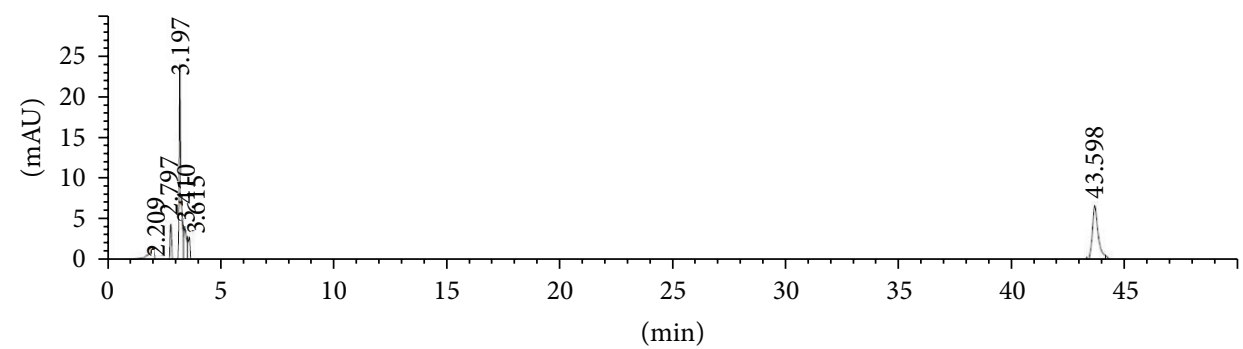

(c)

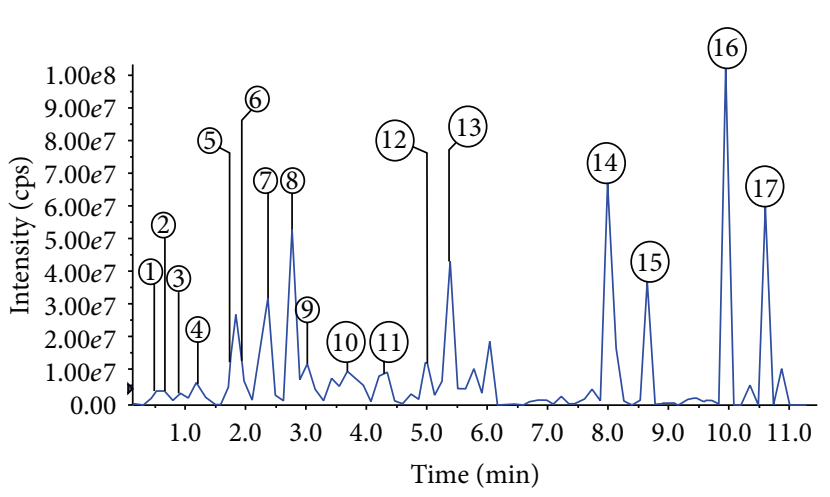

(d)

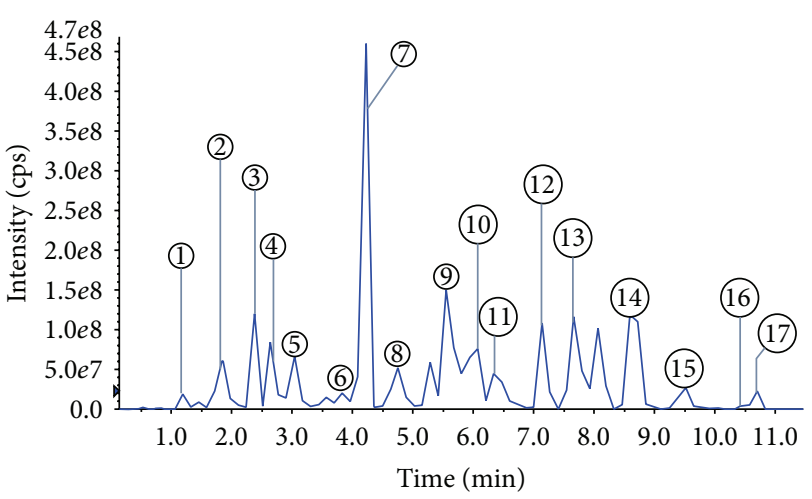

(e)

Figure 3: HPLC fingerprints and LC-MS/MS chromatograms. HPLC-DAD (254 nm) fingerprints of (a) $0.5 \%$, (b) $1.0 \%$, and (c) $1.5 \%$ w/w Moringa oleifera leaves extracts and LC-MS/MS (254 nm) chromatograms of (d) $0.5 \% \mathrm{w} / \mathrm{w}$ Moringa oleifera leaves extracts alone and (e) $0.5 \% \mathrm{w} / \mathrm{w}$ Moringa oleifera leaves meal with nutritional feed.

the unique peaks of the $0.5 \% \mathrm{w} / \mathrm{v}$ MOLE identified these peaks as flavonoids with the major constituents of vitamins, carotenoids, and a few organic acids and inositol derivatives (Figure 3(d)). In addition, for comparative analysis, LCMS/MS analysis of the $0.5 \% \mathrm{w} / \mathrm{w}$ MOLM extract with the same gradient program revealed the presence of isoflavones, phenols, phospholipids, and fatty acids and few flavonoids (Figure 3(e)). These compounds from the $0.5 \% \mathrm{w} / \mathrm{v}$ MOLE and $0.5 \% \mathrm{w} / \mathrm{w}$ MOLM have been tentatively identified and listed in Table 3(a) as apigenin, quercetin, kaempferol derivative, zeaxanthin, tryptophan, succinic acid conjugate, cinnamic acid conjugate, 4-p-coumaroylquinic acid, and ellagic acid conjugate and in Table 3(b) as diazin, daidzein, genistein, formononetin, ellagic acid conjugate, dimethoxyflavone conjugate, lysophosphatidylinositols, methyl stearate, linoleic acid, oleic acid, stearic acid, methyl ester fatty acids, and 
TABLE 3: LC-MS/MS-compound identification.

(a) Compounds identified from the chromatogram of $0.5 \% \mathrm{w} / \mathrm{w}$ Moringa oleifera leaves extracts

\begin{tabular}{|c|c|c|c|c|}
\hline Peak & $\begin{array}{c}\text { Retention time } \\
\text { (RT) }\end{array}$ & $\begin{array}{l}\text { Molecular ion } \\
\text { peak }(\mathrm{M}-\mathrm{H})^{-}\end{array}$ & $\mathrm{MS}^{2}$ fragment ions intensity & Tentative compounds identified \\
\hline 1 & 0.52 & 117 & $73(100), 99,72$ & Succinic acid conjugate \\
\hline 2 & 0.65 & 164 & $147(100), 119,103,72$ & Cinnamic acid conjugate \\
\hline 3 & 0.92 & 203 & $116(100), 142,159$ & Tryptophan \\
\hline 4 & 1.19 & 337 & $191,163,119(100)$ & 4-p-Coumaroylquinic acid \\
\hline 5 & 1.85 & 593 & $383,353(100), 325,297$ & Apigenin-6,8-di-C- $\beta$-D-glucopyranoside \\
\hline 6 & 2.24 & 432 & $284(100), 283,312,269$ & Apigenin 6 C glucoside (isovitexin) \\
\hline 7 & 2.36 & 252 & $208,151,164,107(100)$ & Zeaxanthin derivative \\
\hline 8 & 2.78 & 266 & $222,178,170(100), 151$ & Unknown \\
\hline 9 & 3.04 & 301 & $257,108(100), 109,65$ & Quercetin \\
\hline 10 & 3.73 & 330 & $294,230,224,212(100)$ & 3,30-di-O-Methyl ellagic acid conjugate \\
\hline 11 & 4.31 & 309 & $291,263,251,247,211,197$ (100), 171 & Unknown \\
\hline 12 & 5.03 & 481 & $283,255(100), 224,168,153$ & Kaempferol derivative \\
\hline 13 & 5.42 & 480 & 285,255 (100), 242, 224, 168 & Kaempferol derivative \\
\hline 14 & 8.07 & 856 & $596,575,431,297,279$ (100), 241, 153 & \multirow{4}{*}{ Inositol derivatives } \\
\hline 15 & 8.72 & 739 & 279 (100), 241, 153 & \\
\hline 16 & 10.04 & 858 & 279 (100), 241, 153 & \\
\hline 17 & 10.7 & 832 & 277,255 (100), 241, 153 & \\
\hline
\end{tabular}

(b) Compounds identified from the chromatogram of $0.5 \% \mathrm{w} / \mathrm{w}$ Moringa oleifera leaves extracts with nutritional feed

\begin{tabular}{lcccc}
\hline Peak & $\begin{array}{c}\text { Retention time } \\
(\mathrm{RT})\end{array}$ & $\begin{array}{c}\text { Molecular ion } \\
\text { peak }(\mathrm{M}-\mathrm{H})^{-}\end{array}$ & MS $^{2}$ fragment ions intensity & Tentative compounds identified \\
\hline 1 & 1.18 & 253 & $223,180,81(100), 80$ & Diazin \\
2 & 1.85 & 253 & $223(100), 208,180,132,81$ & Daidzein \\
3 & 2.37 & 269 & $159,133,65(100), 63$ & Genistein \\
4 & 2.65 & 253 & $223(100), 208,180,167,133$ & Formononetin \\
5 & 3.00 & 269 & $159,134,65(100), 63$ & Genistein \\
6 & 3.83 & 376 & $296,278,192,133,80(100)$ & Unknown \\
7 & 4.22 & 393 & $295,283,201,183(100), 301,224,209,183$ & Ellagic acid conjugate \\
8 & 4.75 & 313 & $277(100), 233,183,195,171$ & Dimethoxyflavone conjugate \\
9 & 5.57 & 295 & $297,282(100), 255$ & Unknown \\
10 & 6.08 & 572 & $279(100), 261,244$ & Lysophosphatidylinositols \\
11 & 6.38 & 299 & $256(100), 255$ & Methyl stearate \\
12 & 7.14 & 280 & $281(100), 253$ & Linoleic acid \\
13 & 7.68 & 281 & $311(100), 255,171,125$ & Oleic acid \\
14 & 8.65 & $301,255,171(100)$ & Stearic acid \\
15 & 9.5 & 382 & $311(100), 255,169,125$ & Methyl ester fatty acids \\
16 & 10.5 & 364 & 384 & Quercetin
\end{tabular}

quercetin based on the literature [23-27]/ACD labs mass spectral library.

\section{Discussion}

4.1. Broiler Performance. Growth performance is a primary factor for determining the productivity of broiler chickens. The results indicate that MOLM significantly improves the growth performance of broilers, which is consistent with Ayssiwede et al. [20] who reported that $M$. oleifera leaf meal added to broiler diets significantly increased the average daily weight gain of the broilers. The feed conversion ratio is used to determine the performance of the animals and is obtained by dividing the feed intake by the weight gained. A low FCR is a good indication of high quality feed [28]. In accordance, the MOLM feed supplement increases the performance of 
the chickens. However, The FCR and FI results show no significant differences for the birds supplemented with MOLM which is consistent with [20]. Approximately, 2\% mortality was observed among all the groups except group T2 with 8\% which is considered due to anomaly as in previous studies it has been reported that the addition of MO leaf meal as a feed supplement does not produce any adverse effects on the health and mortality of broiler chickens [29]. Thus, the MO leaf meal is excluded as a factor for the raise in the mortality rate but plays a major role in improving growth performance of chicken as it is enriched with nutritional constituents.

The dressing percentage is a trait of economic importance, and the higher the dressing percentage the better the economic returns [30]. However, the results obtained were relatively less than the findings of Ayssiwede et al. [20] and Zanu et al. [29], who observed percentages ranging from 74 to $77 \%$ and 79 to $81 \%$, respectively. This may be because of environmental and climatic variations. The water holding capacity (WHC) is the most important qualitative characteristic of meat because it affects the appearance of the product, cooking behavior, and juiciness [30]. The WHC of meat is related to the amount of free water released by the meat when subjected to physical pressure or force. The WHCs were examined in terms of drip loss, release of water from the meat without external pressure, and cooking loss, loss of water due to cooking. The treatment groups (T2, T3, and T4) exhibited higher drip loss values compared to the control group (T1), possibly due to an increase in abdominal fat yield and greater glycogen content in the meat from the broilers fed MO leaves [19]. Omojola et al. [30] stated that meat with less cooking loss would give a higher yield per unit cut. Consequently, group T2 $(0.5 \% \mathrm{w} / \mathrm{w})$, which had the lowest cooking loss of $16.62 \%$, had a higher yield of broiler meat. This supports the previous results of Nkukwana et al. [22] who showed that a low percentage of leaf meal inclusion in broiler diets significantly improves broiler performance. The color of raw poultry meat is critical for consumer selection, and the major contributing factors to poultry meat color are myoglobin content, meat $\mathrm{pH}$, intramuscular fat, and moisture content. However, the lightness of broiler chicken meat is more significant than the other colors because it is $100 \%$ white fibers and is the most preferable because of its attractiveness and acceptance among consumers. Accordingly, the results indicate that the treatment groups have significantly higher meat lightness compared to the control group (T1), possibly due to the beta-carotene consumed by chickens fed the MOLM supplement [31].

Meat tenderness is a function of collagen content, heat stability, and myofibrillar structure of the muscle. Meat tenderness significantly improves with muscle aging because of the breakdown of myofibrillar proteins. Tenderness is an important attribute that consumers consider when purchasing chicken meat [32]. The shear value indicates the degree of tenderness. The MO leaves treated chickens exhibited good meat tenderness, especially group T2 $(0.5 \% \mathrm{w} / \mathrm{w})$. This is consistent with the results of Muchenje et al. [33], who reported that when an animal is given supplementary feed, it accrues more intramuscular fat than the one that is not provided supplemental feed. Meat juiciness is directly related to the intramuscular lipids and moisture content of meat and improves tenderness.

Cumulatively, the results of the growth performance, carcass, and meat quality assays indicate that broilers fed MOLM feed supplement show significant $(P<0.05)$ improvement in health status, performance, and meat quality compared to the control group fed only conventional feed. However, consistently varying results (i.e., T4 exhibiting low FCR with high performance; T3 exhibiting improvement in carcass yield; and T2 exhibiting high meat tenderness) were obtained for the MOLM treated groups (T2, T3, and T4). This makes it difficult to select the optimal concentration of MOLM based on the growth performance, carcass, and meat quality. However, $0.5 \% \mathrm{w} / \mathrm{w}$ MOLM fed group retained the meat tenderness, which is an important factor for commercialization. Furthermore, the efficiency of the MO supplement was evaluated.

4.2. Antioxidant Analysis. The results of the in vitro antioxidant activity assays indicate that the MOLE extracts show high radical scavenging activity and total antioxidant capacity compared to the MOLM extracts. The order of antioxidant activity/capacity was as follows: $0.5 \% \mathrm{w} / \mathrm{v}$ MOLE > $0.5 \% \mathrm{w} / \mathrm{w}$ MOLM $>1.0 \% \mathrm{w} / \mathrm{v}$ MOLE $>1.0 \% \mathrm{w} / \mathrm{w}$ MOLM $>$ $1.5 \% \mathrm{w} / \mathrm{v}$ MOLE $>1.5 \% \mathrm{w} / \mathrm{w}$ MOLM $>0 \% \mathrm{w} / \mathrm{w}$ MOLM (only nutritional feed). These results support a previous report indicating aqueous MOLE exhibit high antioxidant activity that may be attributed to phytoconstituents, such as polyphenols, tannins, anthocyanin, glycosides, and thiocarbamates that scavenge free radicals, activate antioxidant enzymes, and inhibit oxidases [34]. In the form of feed supplement (MOLM), the efficiency of the MO leaf extract is lower than the leaf extract alone; however, compared to the nutritional feed alone, the MOLM shows higher activity, supporting the results of Liu et al. [35] and Eloff [36]. In addition, chickens do not voluntarily consume MO leaves; therefore, MOLM can be used as a feed supplement to increase broiler performance [37]. However, based on these evidences, among the evaluated concentrations, $0.5 \%$ w/w MOLM shows the high antioxidant activity due to enriched antioxidant supplement from MO leaves.

In accordance with the in vitro results, $0.5 \mathrm{w} / \mathrm{w}$ MOLM exhibited lowest MDA level and highest SOD, CAT, and GPx activity in both liver and tissue. This is due to the MOLM supplement, enriched with phenolics, flavonoids, and vitamin $\mathrm{C}$, inhibits the formation of free radicals, and contributes to the retention of muscles and organs and lipid stabilization. This result is consistent with the data for meat quality improvement, in which the T2 group $(0.5 \% \mathrm{w} / \mathrm{w})$ has a significantly higher meat tenderness value compared to the other groups. Therefore, the addition of $0.5 \% \mathrm{w} / \mathrm{w} \mathrm{MO}$ with conventional feed (MOLM) retains meat quality by reducing the activity of lipid peroxidation.

Overall, the results indicated that broilers fed the MOLM supplement have significantly better performance and antioxidant status compared to the control fed only nutritional feed. For the percentage of MOLM added to the conventional meal, although the results of the growth performance and carcass and meat quality show some inconsistencies, 
the T2 $(0.5 \% \mathrm{w} / \mathrm{w}$ MOLM) group showed significantly higher in vitro and in vivo antioxidant activity, which is consistent with increased meat quality.

4.3. The Antagonistic Behavior of Bioactive Constituents between MOLE and MOLM. Though antioxidant assay results convincingly revealed $0.5 \% \mathrm{w} / \mathrm{w}$ MOLM as the optimal gradient for feed supplement, the in vitro results specified that generally MOLE exhibit higher antioxidant activity than MOLM, and this drives us to analyze the role of constituents in the activity. In accordance, firstly the comparative analysis of the $0.5 \% \mathrm{w} / \mathrm{v}, 1.0 \% \mathrm{w} / \mathrm{v}$, and $1.5 \% \mathrm{w} / \mathrm{v}$ MOLE using HPLC revealed that $0.5 \% \mathrm{w} / \mathrm{v}$ exhibit few unique peaks further confirmed as flavonoids using LC-MS/MS. In the previous study, the presence of apigenin, quercetin, and kaempferol has been reported in $M$. oleifera leaves, which are responsible for its antioxidant activity [9]. This was also consistent with results of a study by Siddhuraju and Becker [15]. Thus, MOLE are enriched with antioxidant boosting flavonoids.

Secondly, LC-MS/MS was further used to compare and identify compounds in the $0.5 \% \mathrm{w} / \mathrm{v}$ MOLE and $0.5 \% \mathrm{w} / \mathrm{w}$ MOLM (T2) and their role in meat antioxidant status. As anticipated, $0.5 \% \mathrm{w} / \mathrm{v}$ MOLE exhibited high expression of flavonoids. Previously Gupta et al. [38] isolated quercetin and kaempferol from $M$. oleifera leaf extract and identified their antidiabetic property as restoring the antioxidant status in streptozotocin-induced diabetic rats. Qwele [39] also reported the presence of zeaxanthin and tryptophan in $M$. oleifera leaves and categorized them as antioxidant compounds because they enhance endogenous antioxidant enzyme levels. Coppin [40] reported the presence of coumaroylquinic acid, and Sinha et al., 2012 [41], reported the presence of ellagic acid conjugate in $M$. oleifera leaves, which may prevent hepatic lipid peroxidation by scavenging free radicals. Together, these results indicate that $0.5 \% \mathrm{w} / \mathrm{v}$ MOLE are enriched with antioxidant compounds, such as flavonoids, vitamins, carotenoids, and a few organic acids, which may be responsible for its enhanced antioxidant activity.

On contrast, $0.5 \% \mathrm{w} / \mathrm{w}$ MOLM possesses a high amount of isoflavones, phospholipids, and fatty acids, possibly from the soy and corn ingredients of feed. In a previous study, $\mathrm{He}$ and Chen [42] reported the occurrence of the isoflavone diazin and its aglycones, daidzein, genistein, and formononetin in soybeans. This clearly indicates that the isoflavones in the $0.5 \mathrm{w} / \mathrm{w}$ MOLM supplement may be from the soy in the conventional feed mix. These compounds exert antioxidant and anticarcinogenic effects in the skin of hairless mice and protect cells against oxidative DNA damage [43]. However, these isoflavones exhibit less potent antioxidant activity than flavonoids and also show antagonism against the antioxidant activity of flavonoids, as reported by Choi et al. [44]. The chromatographic analysis also showed high level expression of fatty acids, such as linoleic acid, oleic acid, stearic acid, and methyl ester fatty acids, which are expressed in $M$. oleifera leaves, soy, and corn and are consistent with a previous report [45]. The LC MS/MS analysis results clearly support the antioxidant results, in which MOLE have high antioxidant activity because of the high expression of flavonoids, which was suppressed in MOLM because of the antagonistic role of isoflavones (from conventional feed) against flavonoids (from MO leaves). However, MOLM exhibits less potent antioxidant activity because of the presence of isoflavones, quercetin, and fatty acids.

\section{Conclusion}

Conclusively, during MOLM preparation, the compounds in the conventional feed, such as the isoflavones, phospholipids, and fatty acids, antagonistically inhibit the expression/activity of the flavonoids and phenols in the MO leaves. Therefore, $0.5 \% \mathrm{w} / \mathrm{w}$ MOLM showed relatively low antioxidant activity compared to the $0.5 \% \mathrm{w} / \mathrm{v}$ MOLE. However, isoflavones, phospholipids, and fatty acids also possess antioxidant effects, relatively less than flavonoids. Consequently, the chickens fed 0.5\% w/w MOLM feed supplement showed the highest antioxidant activity compared to the other treatment and control groups. Thus, optimizing the gradient of soy and corn in the conventional nutrition feed with $0.5 \% \mathrm{w} / \mathrm{w}$ of MOLE might help the researchers/nutritional feed corps/farmers to provide an efficient and cost-effective feed for broilers.

\section{Conflict of Interests}

The authors have declared no conflict of interests.

\section{Acknowledgments}

This research work was supported by research grants from Ministry of Science, Technology and Innovation of Malaysia under E-science Project number 02-01-04-SF1144 and Ministry of Agriculture Malaysia under science fund (agriculture section) number 05-01-04-SF1148.

\section{References}

[1] GLOBAL POULTRY TRENDS 2013: Russia and Ukraine Lead Europe's Growth, 2013, http://www.thepoultrysite.com/ articles/2954/global-poultry-trends-2013-russia-and-ukrainelead-europes-growth.

[2] "USDA livestock, dairy and poultry outlook," January 2014, http://www.thepoultrysite.com/reports/?id=3327.

[3] A. Brenes and E. Roura, "Essential oils in poultry nutrition: main effects and modes of action," Animal Feed Science and Technology, vol. 158, no. 1-2, pp. 1-14, 2010.

[4] A. Miezeliene, G. Alencikiene, R. Gruzauskas, and T. Barstys, "The effect of dietary selenium supplementation on meat quality of broiler chickens," Biotechnologie, Agronomie, Société et Environnement, vol. 15, no. 1, pp. 61-69, 2011.

[5] D. Milićević, D. Vranić, Z. Mašić et al., "The role of total fats, saturated/unsaturated fatty acids and cholesterol content in chicken meat as cardiovascular risk factors," Lipids in Health and Disease, vol. 13, no. 1, article 42, 2014.

[6] S. Gorelik, M. Ligumsky, R. Kohen, and J. Kanner, "The stomach as a 'bioreactor': when red meat meets red wine," Journal of Agricultural and Food Chemistry, vol. 56, no. 13, pp. 5002-5007, 2008. 
[7] W. A. Dozier III, M. T. Kidd, A. Corzo, J. Anderson, and S. L. Branton, "Dietary amino acid responses of mixed-sex broiler chickens from two to four kilograms," Journal of Applied Poultry Research, vol. 16, no. 3, pp. 331-343, 2007.

[8] G. R. Sampaio, T. Saldanha, R. A. M. Soares, and E. A. F. S. Torres, "Effect of natural antioxidant combinations on lipid oxidation in cooked chicken meat during refrigerated storage," Food Chemistry, vol. 135, no. 3, pp. 1383-1390, 2012.

[9] G. Karthivashan, M. Tangestani Fard, P. Arulselvan, F. Abas, and S. Fakurazi, "Identification of bioactive candidate compounds responsible for oxidative challenge from hydro-ethanolic extract of moringa oleifera leaves," Journal of Food Science, vol. 78, no. 9, pp. C1368-C1375, 2013.

[10] S. Fakurazi, I. Hairuszah, and U. Nanthini, "Moringa oleifera Lam prevents acetaminophen induced liver injury through restoration of glutathione level," Food and Chemical Toxicology, vol. 46, no. 8, pp. 2611-2615, 2008.

[11] S. A. Sharifudin, S. Fakurazi, M. T. Hidayat, I. Hairuszah, M. A. M. Moklas, and P. Arulselvan, "Therapeutic potential of Moringa oleifera extracts against acetaminophen-induced hepatotoxicity in rats," Pharmaceutical Biology, vol. 51, no. 3, pp. 279-288, 2013.

[12] S. Fakurazi, S. A. Sharifudin, and P. Arulselvan, "Moringa oleifera hydroethanolic extracts effectively alleviate acetaminophen-induced hepatotoxicity in experimental rats through their antioxidant nature," Molecules, vol. 17, no. 7, pp. 8334-8350, 2012.

[13] A. A. Muhammad, N. A. S. Pauzi, P. Arulselvan, F. Abas, and S. Fakurazi, "In vitro wound healing potential and identification of bioactive compounds from Moringa oleifera lam," BioMed Research International, vol. 2013, Article ID 974580, 10 pages, 2013.

[14] S. Fakurazi, I. Hairuszah, and U. Nanthini, "Moringa oleifera Lam prevents acetaminophen induced liver injury through restoration of glutathione level," Food and Chemical Toxicology, vol. 46, no. 8, pp. 2611-2615, 2008.

[15] P. Siddhuraju and K. Becker, "Antioxidant properties of various solvent extracts of total phenolic constituents from three different agroclimatic origins of drumstick tree (Moringa oleifera Lam.) leaves," Journal of Agricultural and Food Chemistry, vol. 51, no. 8, pp. 2144-2155, 2003.

[16] E. M. B. Teixeira, M. R. B. Carvalho, V. A. Neves, M. A. Silva, and L. Arantes-Pereira, "Chemical characteristics and fractionation of proteins from Moringa oleifera Lam. leaves," Food Chemistry, vol. 147, pp. 51-54, 2014.

[17] A.-M. Donkor, R. L. K. Glover, D. Addae, and K. A. Kubi, "Estimating the nutritional value of the leaves of Moringaoleifera on poultry," Food and Nutrition Sciences, vol. 4, no. 11, pp. 10771083, 2013.

[18] A. M. V. Kakengi, J. T. Kaijage, S. V. Sarwatt, S. K. Mutayoba, M. N. Shem, and T. Fujihara, "Effect of Moringa oleifera leaf meal as a substitute for sunflower seed meal on performance of laying hens in Tanzania," Livestock Research for Rural Development, vol. 19, no. 8, 2007.

[19] A. Ologhobo, E. I. Akangbe, I. O. Adejumo, and O. Adeleye, "Effect of moringa oleifera leaf meal as replacement for oxytetracycline on carcass characteristics of the diets of broiler chickens," Annual Research \& Review in Biology, vol. 4, no. 2, pp. 423-431, 2014.

[20] S. B. Ayssiwede, A. Dieng, H. Bello et al., "Effects of Moringa oleifera (Lam.) leaves meal incorporation in diets on growth performances, carcass characteristics and economics results of growing indigenous senegal chickens," Pakistan Journal of Nutrition, vol. 10, no. 12, pp. 1132-1145, 2011.

[21] T. T. Nkukwana, V. Muchenje, P. J. Masika, L. C. Hoffman, K. Dzama, and A. M. Descalzo, "Fatty acid composition and oxidative stability of breast meat from broiler chickens supplemented with Moringa oleifera leaf meal over a period of refrigeration," Food Chemistry, vol. 142, pp. 255-261, 2014.

[22] T. T. Nkukwana, V. Muchenje, E. Pieterse et al., "Effect of Moringa oleifera leaf meal on growth performance, apparent digestibility, digestive organ size and carcass yield in broiler chickens," Livestock Science, vol. 161, no. 1, pp. 139-146, 2014.

[23] J. K. Prasain, K. Jones, M. Kirk et al., "Profiling and quantification of isoflavonoids in kudzu dietary supplements by highperformance liquid chromatography and electrospray ionization tandem mass spectrometry," Journal of Agricultural and Food Chemistry, vol. 51, no. 15, pp. 4213-4218, 2003.

[24] B. Harbaum, E. M. Hubbermann, C. Wolff, R. Herges, Z. Zhu, and K. Schwarz, "Identification of flavonoids and hydroxycinnamic acids in pak choi varieties (Brassica campestris L. ssp. chinensis var. communis) by HPLC-ESI-MS ${ }^{n}$ and NMR and their quantification by HPLC-DAD," Journal of Agricultural and Food Chemistry, vol. 55, no. 20, pp. 8251-8260, 2007.

[25] R. C. Simas, R. R. Catharino, I. B. S. Cunha et al., "Instantaneous characterization of vegetable oils via TAG and FFA profiles by easy ambient sonic-spray ionization mass spectrometry," Analyst, vol. 135, no. 4, pp. 738-744, 2010.

[26] L. Barros, M. Dueñas, A. M. Carvalho, I. C. F. R. Ferreira, and C. Santos-Buelga, "Characterization of phenolic compounds in flowers of wild medicinal plants from Northeastern Portugal," Food and Chemical Toxicology, vol. 50, no. 5, pp. 1576-1582, 2012.

[27] D. de Beer, A. E. Schulze, E. Joubert, A. de Villiers, C. J. Malherbe, and M. A. Stander, "Food ingredient extracts of Cyclopia subternata (Honeybush): variation in phenolic composition and antioxidant capacity," Molecules, vol. 17, no. 12, pp. 14602-14624, 2012.

[28] P. Hascik, M. Kacaniova, M. Mihok, J. Pochop, and E. Benczova, "Performance of various broiler chicken hybrids fed with commercially produced feed mixtures," International Journal of Poultry Science, vol. 9, no. 11, pp. 1076-1082, 2010.

[29] H. K. Zanu, P. Asiedu, M. Tampuori, M. Abada, and I. Asante, "Possibilities of using Moringa (Moringa oleifera) leaf meal as a partial substitute fish meal in broiler chickens diets," Online Journal of Animal and Feed Research, vol. 2, no. 1, pp. 70-75, 2012.

[30] A. B. Omojola, A. O. K. Adesehinwa, H. Madu, and S. Attah, "Effect of sex and slaughter weight on broiler chicken carcass," The Journal of Food, Agriculture and Environment, vol. 2, no. 3-4, pp. 61-63, 2004.

[31] C. Wapi, T. T. Nkukwana, L. C. Hoffman et al., "Physicochemical shelf-life indicators of meat from broilers given Moringa oleifera leaf meal," South African Journal of Animal Sciences, vol. 43, no. 5, pp. S43-S47, 2013.

[32] P. R. Kriese, A. L. Soares, P. D. Guarnieri, S. H. Prudencio, E. I. Ida, and M. Shimokomaki, "Biochemical and sensorial evaluation of intact and boned broiler breast meat tenderness during ageing," Food Chemistry, vol. 104, no. 4, pp. 1618-1621, 2007.

[33] V. Muchenje, K. Dzama, M. Chimonyo, P. E. Strydom, A. Hugo, and J. G. Raats, "Sensory evaluation and its relationship to physical meat quality attributes of beef from Nguni and Bonsmara steers raised on natural pasture," Animal, vol. 2, no. 11, pp. 1700-1706, 2008. 
[34] S. Luqman, S. Srivastava, R. Kumar, A. K. Maurya, and D. Chanda, "Experimental assessment of Moringa oleifera leaf and fruit for its antistress, antioxidant, and scavenging potential using in vitro and in vivo assays," Evidence-Based Complementary and Alternative Medicine, vol. 2012, Article ID 519084, 12 pages, 2012.

[35] X. D. Liu, A. Jang, B. D. Lee, S. K. Lee, M. Lee, and C. Jo, "Effect of dietary inclusion of medicinal herb extract mix in a poultry ration on the physico-chemical quality and oxidative stability of eggs," Asian-Australasian Journal of Animal Sciences, vol. 22, no. 3, pp. 421-427, 2009.

[36] J. N. Eloff, "A mixture of plant extracts can be more effective than a commercial antibacterial feed additive in poultry challenged with Clostridium perfringens," African Journal of Traditional, Complementary and Alternative Medicine, vol. 5, p. 468, 2008, Proceedings of the World Conference on Medicinal and Aromatic Plants IV, Cape Town, South Africa, November 2008.

[37] H. P. Portugaliza and T. J. Fernandez Jr., "Growth performance of Cobb broilers given varying concentrations of Malunggay (Moringa oleifera Lam.) aqueous leaf extract," Online Journal of Animal and Feed Research, vol. 2, no. 6, pp. 465-469, 2012.

[38] R. Gupta, M. Mathur, V. K. Bajaj et al., "Evaluation of antidiabetic and antioxidant activity of Moringa oleifera in experimental diabetes," Journal of Diabetes, vol. 4, no. 2, pp. 164171, 2012.

[39] K. Qwele, Antioxidant Activity and the Quality of Meat from Goats and Broilers Supplemented with Moringa (Moringa Oleifera) Leaves, University of Fort Hare, Alice, South Africa, 2011.

[40] J. Coppin, A study of the nutritional and medicinal values of Moringa oleifera leaves from Sub-Saharan Africa: Ghana, Rwanda Senegal and Zambia [M.S. thesis], Rutgers, The State University of New Jersey, 2008.

[41] M. Sinha, D. K. Das, S. Datta, S. Ghosh, and S. Dey, "Amelioration of ionizing radiation induced lipid peroxidation in mouse liver by Moringa oleifera Lam. leaf extract," Indian Journal of Experimental Biology, vol. 50, no. 3, pp. 209-215, 2012.

[42] F.-J. He and J.-Q. Chen, "Consumption of soybean, soy foods, soy isoflavones and breast cancer incidence: differences between Chinese women and women in Western countries and possible mechanisms," Food Science and Human Wellness, vol. 2, no. 3-4, pp. 146-161, 2013.

[43] B. Iovine, M. L. Iannella, F. Gasparri, G. Monfrecola, and M. A. Bevilacqua, "Synergic effect of genistein and daidzein on UVB-induced DNA damage: an effective photoprotective combination," Journal of Biomedicine and Biotechnology, vol. 2011, Article ID 692846, 8 pages, 2011.

[44] E. J. Choi, B. H. Lee, K. Lee, and K.-M. Chee, "Longterm combined administration of quercetin and daidzein inhibits quercetin-induced suppression of glutathione antioxidant defenses," Food and Chemical Toxicology, vol. 43, no. 5, pp. 793-798, 2005.

[45] O. Olorunfemi, I. A. Emmanuel, and O. Stanley, "Comparative study of proximate, amino acids and fatty acids of Moringa oleifera tree," Applied Chemistry-Elixir International Journal, vol. 54, pp. 12543-12554, 2013. 

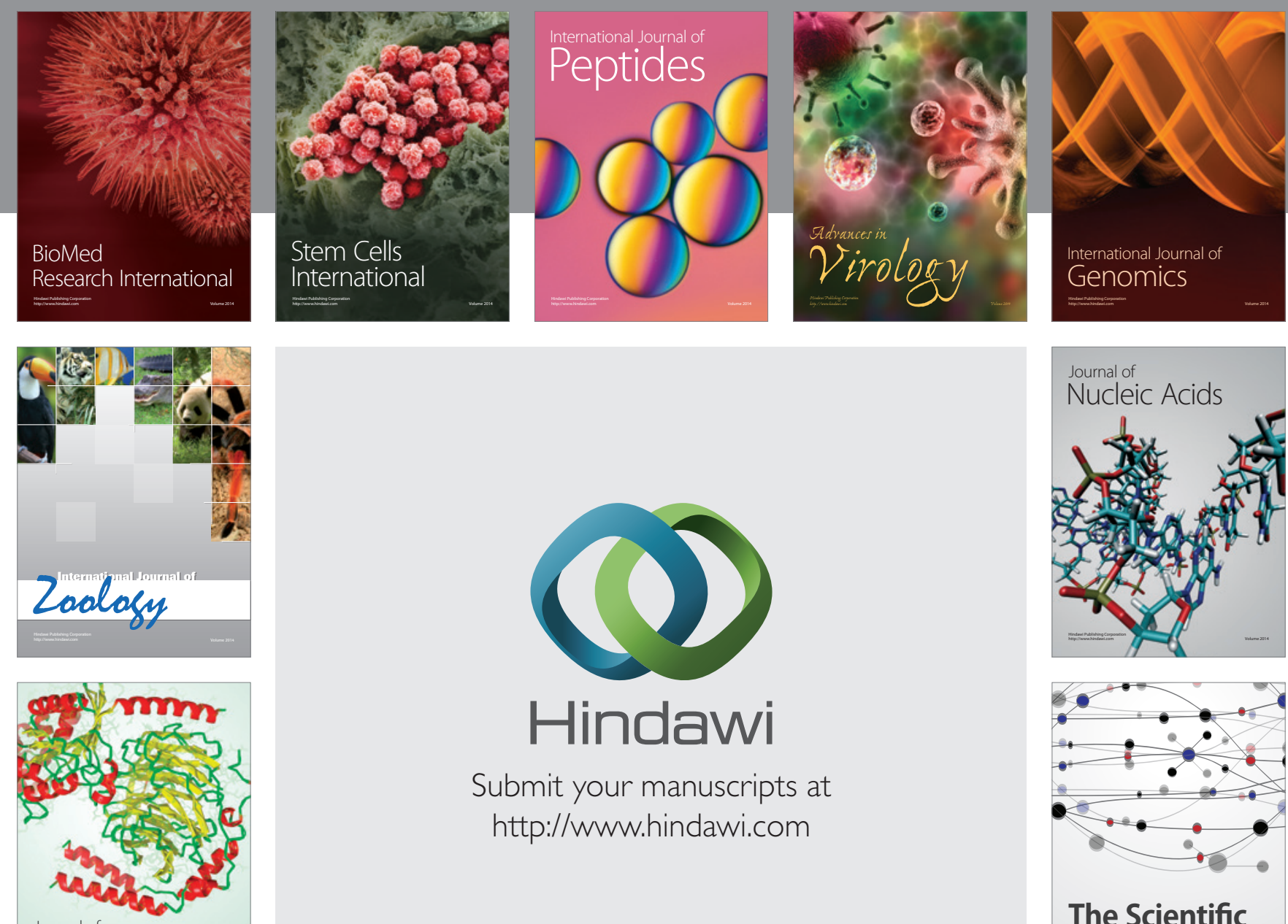

Submit your manuscripts at

http://www.hindawi.com

Journal of
Signal Transduction
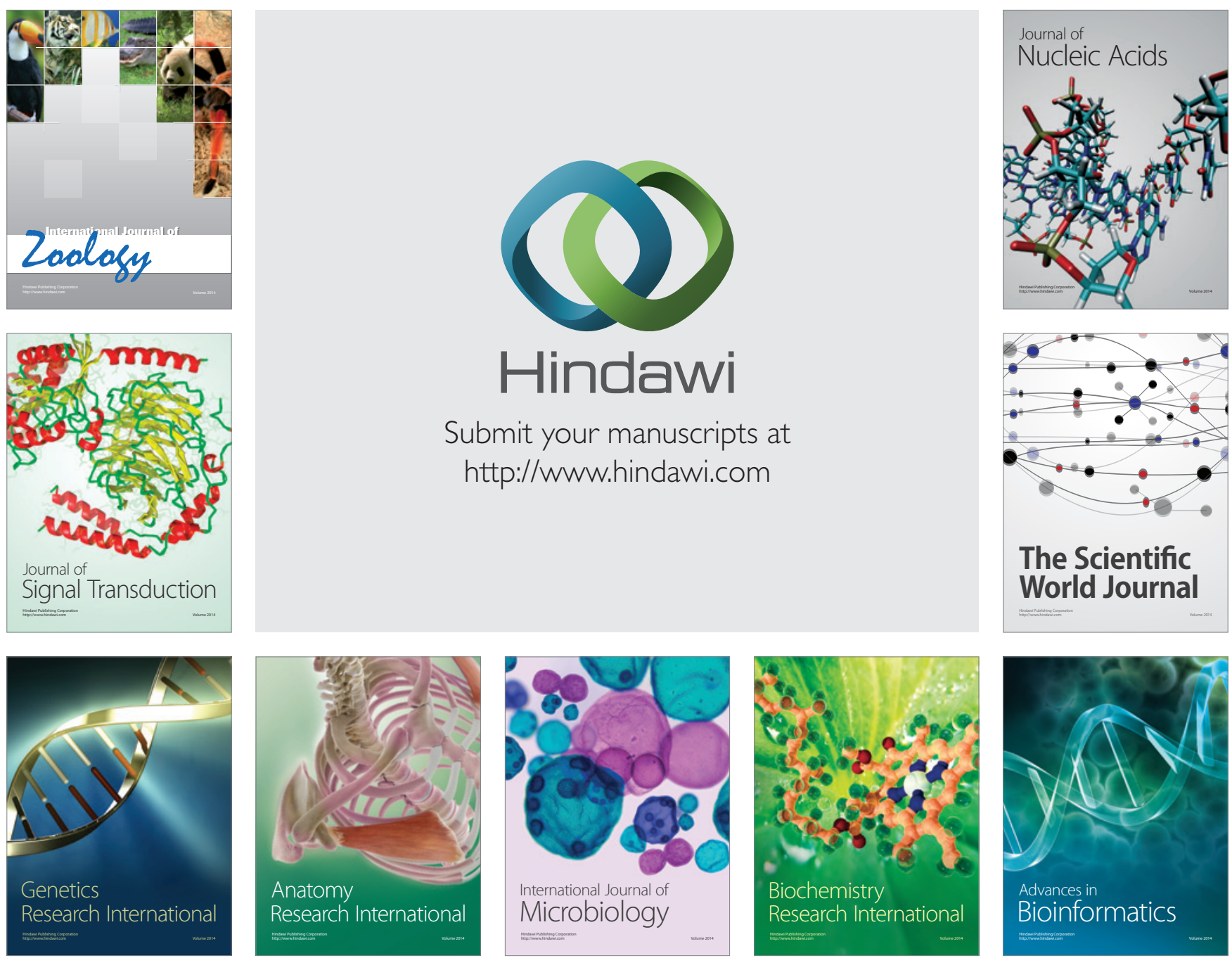

The Scientific World Journal
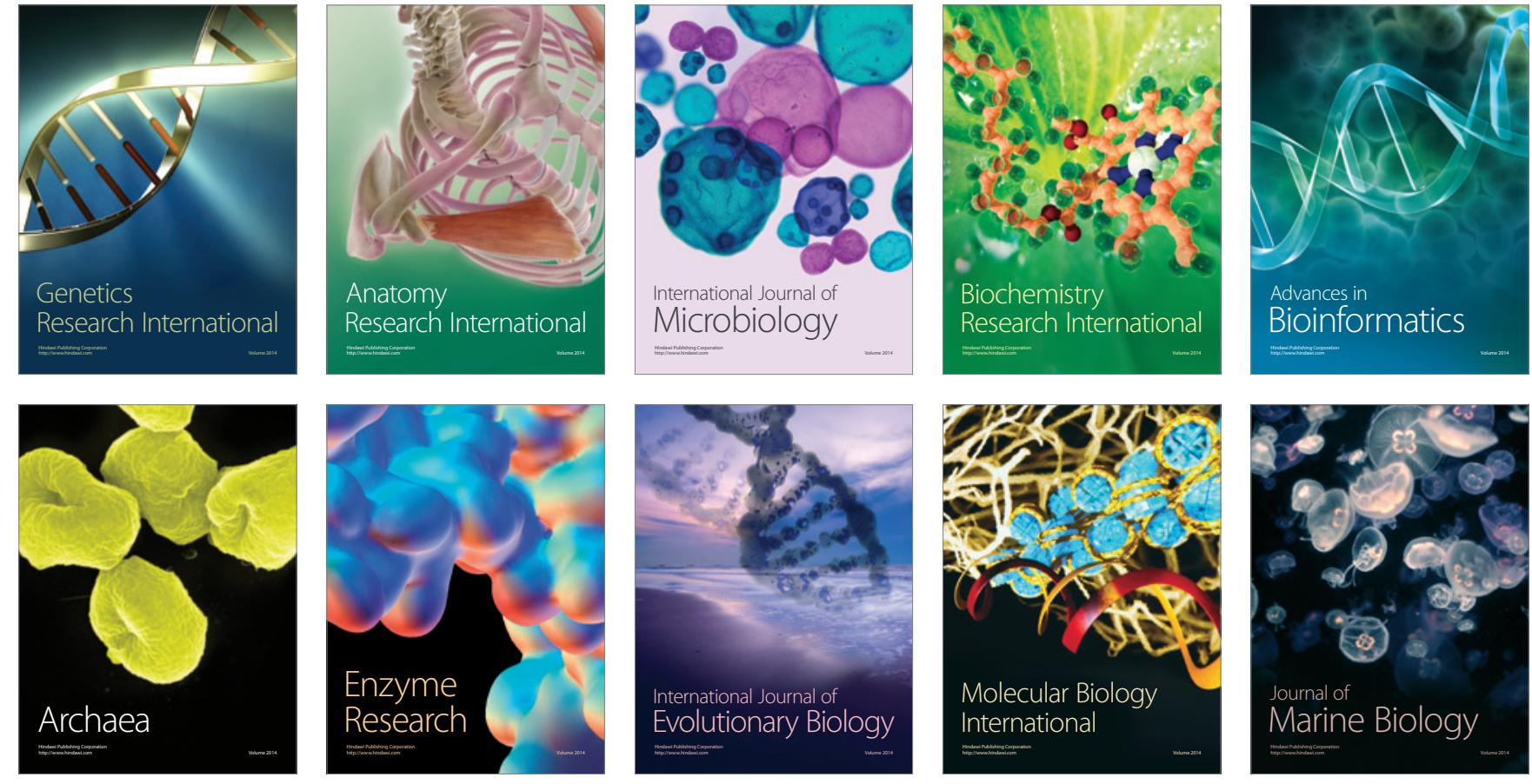